\title{
PROJETO UNIVERSIDADE ESCOLA - A INTEGRAÇÃO DE ESCOLARES NO AMBIENTE ACADÊMICO
}

Ana Paula de Jesus Viana, Angélica de Oliveira Soares, Mayara Alves Vagueira, Fabiola de Sampaio Rodrigues Grazinoli Garrido

Universidade Federal Rural do Rio de Janeiro - UFRRJ/ITR, Três Rios, RJ, E-mail: anaviana.ufrrj@gmail.com, soaresufrri@gmail.com, mayara vagueira@hotmail.com,

Agência de fomento: Programa de Educação Tutorial Conexões Saberes - Três Rios

\section{RESUMO}

A educação é o elemento fundamental de transformação do indivíduo e da realidade que ele vive. Através dela é possível conduzir a busca pelo conhecimento e autonomia, despertando a consciência e responsabilidade socioambiental. Esse trabalho objetivou através do projeto Universidade Escola integrar os alunos do ensino médio à realidade acadêmica vivida dentro da universidade, promover a experiência dos integrantes do PET Conexões de Saberes com a metodologia da problematização, gerar a integração entre os alunos do Instituto Três Rios e escolares do Ensino Médio, otimizar as habilidades de leitura e processamento de textos acadêmicos e de mídia, trabalhar com aprendizagem significativa e escolares. Como metodologia foi adotada pesquisa prévia dos bolsistas do PET sobre os temas dos GT's além da elaboração de uma apresentação sobre a universidade e os projetos nela existentes. Concluímos que esses encontros são fundamentais para compreender a realidade social da comunidade e integrá-la ao ambiente acadêmico.

Palavras-chave: Educação, Responsabilidade Social, Extensão, Integração.

UNIVERSITY SCHOOL PROJECT - The integration of students in the academic environment

\begin{abstract}
Education is the key element of transformation of the individual and the reality he lives. Through it is possible to conduct the search for knowledge and autonomy, raising awareness and environmental responsibility. This study aimed through the project University School integrate high school students to the academic reality experienced within the university, promoting the experience of members of the PET Knowledge Connections with the methodology of questioning, generate integration among students of the Institute Three Rivers and school Secondary Education, optimize the skills of reading and processing of academic texts and media, working with significant learning and school. The methodology was adopted prior research of PET scholars on issues of GT's in addition to the preparation of a presentation about the university and the projects in that area. We conclude that these meetings are key to understanding the social reality of the community and integrate it into the academic environment.
\end{abstract}

Keywords: Education, Social Responsibility, Extension, Integration . 


\section{INTRODUÇÃO}

A educação é um elemento fundamental de transformação do indivíduo e da realidade em que ele vive. De acordo com Piaget (1970) "conhecer é o efeito de um processo ativo de elaboração da realidade (externa ou interna) por parte de aprendiz. Quem aprende não é apenas objeto da ação daquele que ensina, mas sujeito ativo dos processos de conhecer". Dessa forma a construção do conhecimento é um processo dinâmico que se relaciona diretamente com a realidade vivenciada pelo indivíduo, sendo esse o próprio objetivo do trabalho educativo e o aprendizado única razão de ser. De acordo com o Dicionário Aurélio, 1975, "Universidade" é condição de universal. Do latim, universitas, universalidade, totalidade. Sobre a universidade repousa o compromisso de trabalhar ensino, pesquisa e extensão. O artigo 207 da Constituição Federal de 1988 se impõe dizendo que as universidades gozam de autonomia didático-científica que obedeça ao princípio de indissociabilidade entre ensino, pesquisa e extensão. $O$ caderno de Proposta do ANDES-SN para Universidade a Brasileira (ANDES, 2013), ao referir-se aos princípios que fundamentam o padrão de qualidade para a universidade, reafirma: O princípio da indissociabilidade entre ensino, pesquisa e extensão reflete um conceito de qualidade do trabalho acadêmico que favorece a aproximação entre universidade e sociedade, a auto-reflexão crítica, a emancipação teórica e prática dos estudantes e o significado social do trabalho acadêmico. A concretização deste princípio supõe a realização de projetos coletivos de trabalho que se referenciem na avaliação institucional, no planejamento das ações institucionais e na avaliação que leve em conta o interesse da maioria da sociedade. O papel da universidade vai além de promover a formação profissional e científica de pessoal de nível superior, e realizar pesquisa teórica e prática nas áreas do saber humanístico, tecnológico e artístico. Ela deve criar vínculos com a sociedade e permitir que o desenvolvimento social ocorra. Uma das ferramentas utilizadas pelas universidades para cumprir essa prerrogativa é o Programa de Educação Tutorial (PET). Criado em 1979, pela Coordenação de Aperfeiçoamento de Pessoal de Nível Superior - CAPES com o nome Programa Especial de Treinamento - PET, que objetiva ampliar a visão de mundo daqueles que se inserem no modelo foi transferido no ano de 1999 para a Secretaria de Educação Superior do Ministério da Educação, ficando à sua margem sob a responsabilidade do Departamento de Modernização e Programa da Educação Superior - DEPEM. Em 2004 o PET passou a ser identificado como Programa de Educação Tutorial. No ano de 2010 na Universidade Federal Rural do Rio de Janeiro/Instituto Três Rios nasce o PET Conexões dos Saberes para uma Formação Integradora e Cidadã no Município de Três Rios. Trata-se de um grupo multidisciplinar que contempla os cursos presentes no instituto (Administração, Direito, Economia e Gestão Ambiental). Dentre todos os trabalhos desenvolvidos pelo programa vale ressaltar o Projeto Universidade Escola que se propõe a inserir a comunidade e os alunos secundaristas no espaço acadêmico. Esse projeto surge com objetivo de integrar os alunos do ensino médio à realidade acadêmica vivida dentro da universidade, apresentando a estrutura, os cursos, movimento estudantil, as formas de ingresso e principalmente o desenvolvimento do debate de temas atuais como ferramenta de entendimento para que sejam estimulados a pensar e compreender que têm o direito de se apoderar do espaço público e se sensibilizarem quanto ao papel que podem exercer na sociedade. Os objetivos incluem: promover a experiência dos integrantes do PET Conexões de Saberes com a Metodologia da Problematização; promover a integração entre os alunos do Instituto Três Rios e escolares do Ensino Médio; otimizar as habilidades de leitura e processamento de textos acadêmicos e de mídia; trabalhar com aprendizagem significativa e escolares. 


\section{METODOLOGIA}

Para o desenvolvimento do trabalho foram feitas algumas discussões preliminares pelos alunos participantes do PET para elencar temáticas atuais que envolvesse os secundaristas nos Grupos de Trabalhos (GTs). Após definidos os temas que seriam trabalhados, os petianos se dividiram em subgrupos de duas ou três pessoas que desenvolveram durante três meses uma rotina de estudos, planejamento e elaboração de dinâmicas para serem trabalhadas posteriormente. Foi feito um referencial teórico pelos petianos envolvidos através da leitura de artigos científicos e buscas na internet sobre os temas: Drogas, Manifestações de junho, Cotas (2014) e Redução da Maioridade Penal, Corrupção na Petrobrás, Bancos de Perfis de DNA, Crimes Ambientais e distribuição de renda (2015). Em um primeiro momento, levantou-se escolas que tivesse interesse em participar do projeto através de uma carta convite, direcionada aos diretores por e-mail, convidando os alunos de primeiro a terceiro ano do ensino médio. As visitas ocorreram no primeiro semestre de 2014 e no segundo semestre de 2015. A universidade recebeu cerca de 80 jovens escolares, que puderam visitar as instalações, conhecendo laboratórios e biblioteca, além de ouvir relatos de experiência de acadêmicos que falaram sobre a vida acadêmica, movimento estudantil e a realidade vivenciada dentro da academia. No momento seguinte abriram-se vários grupos de discussão, de acordo com o interesse de cada um, onde houve muita troca de informações e vivências. As atividades foram realizadas nas salas de aulas da instituição, utilizando materiais como: Datashow, caixa de som, papéis, canetas, recortes de jornais, vídeos e encenação.

Como o projeto inicial tinha o intuito exclusivamente educacional e os questionários entregues ao final do evento apenas buscavam a opinião dos participantes, respeitando os princípios éticos quanto à não identificação e ao consentimento, o mesmo não foi submetido à análise do CEP. Tal posição é atualmente sustentada pela Resolução CNS no 510 de 2016 que no parágrafo único do art. 1ำ considera que este tipo de pesquisa não deve ser registrada ou avaliada pelo sistema CEP-CONEP.

\section{RESULTADOS}

Foi possível em alguns momentos perceber a ausência de familiaridade dos alunos com o espaço acadêmico. A busca pela sensibilização dos participantes, fazendo com que se percebessem como agentes sociais no ambiente em que estão inseridos, proporcionou também aos acadêmicos uma troca relevante de conhecimento. Através de uma pesquisa de satisfação aplicada por um questionário ao final das atividades, buscou-se compreender a satisfação percebida dos envolvidos. Notou-se que os debates foram considerados como ponto principal por uma grande parcela dos respondentes, o que justifica a hipótese da necessidade de intensificação de trabalhos de extensão, de forma a impactar positivamente a comunidade. $O$ gráfico abaixo apresenta a opinião dos participantes do encontro de 2015 quando perguntados sobre o que mais gostou durante o evento. 
Pesquisa de satisfação realizada entre os participantes

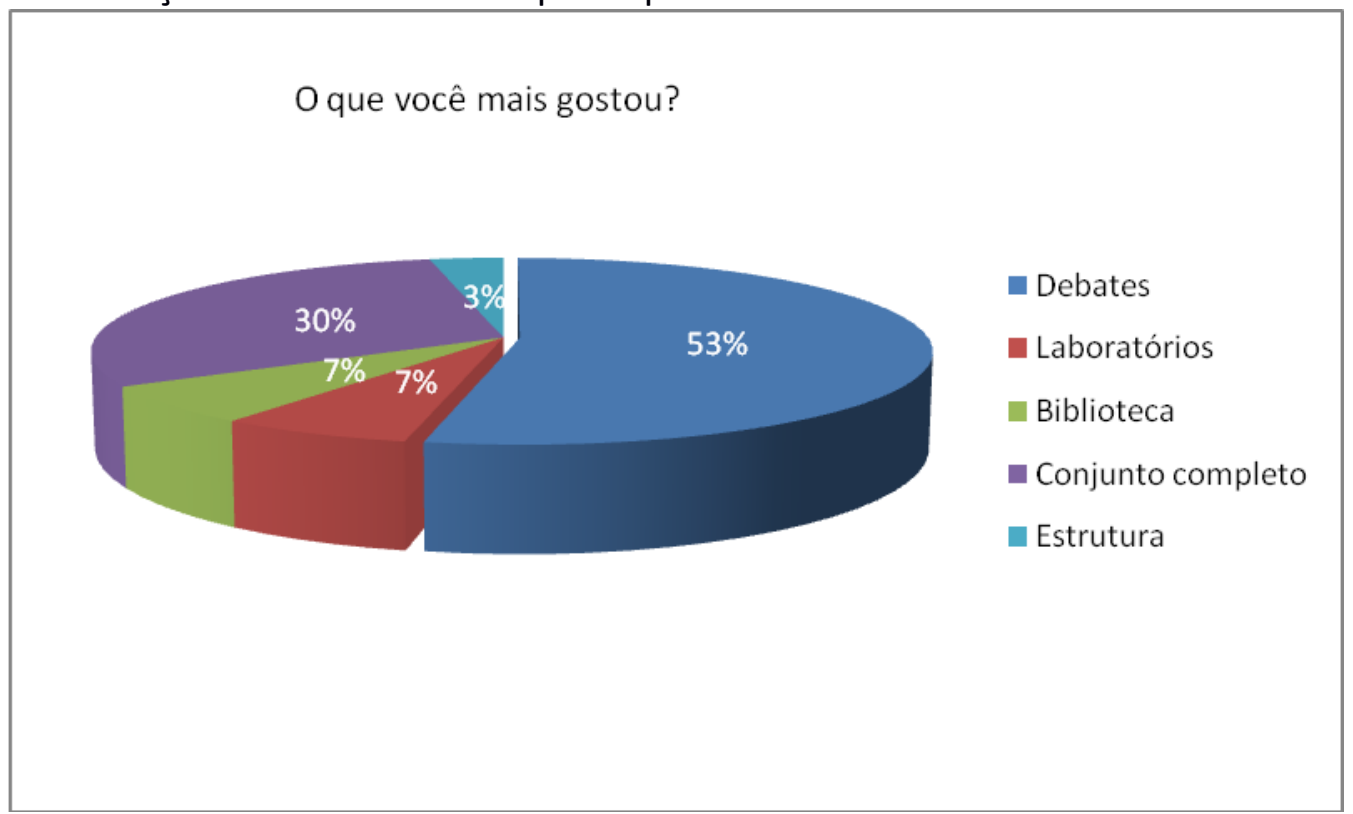

Fonte: Pesquisa realizada com os participantes dos encontros.

A partir da pesquisa inferiu-se que mais da metade dos participantes tiveram um interesse maior nos debates, onde puderam não somente ouvir os mediadores, mas também opinar e se sentir agentes tanto da atividade quanto dos temas propostos, que, por serem temas atuais e que envolvem a sociedade num todo, permeiam também a vida desses jovens.

\section{DISCUSSÃO}

De acordo com Gonçalves Rey (2001) "Entender os conceitos ou as ideias explicitadas por um sujeito, significa compreender a ele próprio e estender nosso olhar para aspectos que o circundam num determinado contexto social." A oportunidade de interagir com escolares apresentou possibilidades de carreiras e apontou a universidade como um local de construção de novos significados. Além da possibilidade de expressarem suas percepções sobre temas relevantes e muito próximos à realidade, o próprio contato com espaços e pessoas que estão integradas à vida acadêmica foi destacado pelos escolares. Assim, a preocupação inicial do grupo foi ultrapassada, transcendendo os limites da educação formal e indo de encontro às questões sociais, tais como empoderamento e apropriação.

O projeto é dinâmico e os temas mudam, mas o contato com os escolares suscita nestes uma compreensão reconstruída da vida acadêmica. Por outro lado, especialmente os bolsistas do programa puderam representar para os escolares exemplos de pessoas que passaram pelas mesmas escolas e que, neste momento, desempenham um papel de co-responsáveis pelo acolhimento e desenvolvimento de outros futuros universitários. Certo é que o efeito do projeto com escolares sobre os acadêmicos é muito marcante. Os futuros profissionais compreendem o sentido da extensão universitária e a importância de carregarem consigo a responsabilidade social em seus futuros empreendimentos e trabalhos.

\section{CONCLUSÃO}

Desde o primeiro encontro percebeu-se que existe uma carência por ações que integrem a comunidade acadêmica com os jovens do entorno, o que despertou nos petianos a necessidade de buscar ações mais atuantes que fomentem a interação entre a universidade e as escolas. Através da proposta Universidade Escola desenvolvida pelo Programa de Educação Tutorial, os pilares de sustentação da universidade puderam ser trabalhados em sua completude, promovendo ensino, pesquisa e extensão. À medida que tais ações foram concretizadas e analisadas pelo grupo, 
entendeu-se a necessidade de tornar tal projeto duradouro na UFRRJ/Instituto Três Rios, configurando um legado que impacte positivamente toda sociedade.

\section{REFERÊNCIAS}

ANDES-SN. Proposta do ANDES-SN para a Universidade Brasileira. Cadernos ANDES no 2. Edição atualizada e revisada. Brasília: ANDES-SN,2013. 50p. Disponível em <http://portal.andes.org.br/imprensa/documentos/imp-doc-811277708.pdf>. Acessado em 27/04/2016.

BRASIL. Constituição (1998). Constituição da República Federativa do Brasil: promulgada em 5 de outubro de 1988. Disponível em <http://www.jusbrasil.com.br/topicos/10650167/artigo-207-daconstituicao-federal-de-1988>.Acessado em 22/04/2016

CNS. Resolução no 510 de 07 de abril de 2016.

DE AZEVEDO, Janete M. Lins. A educação como política pública. Autores Associados, 1997.

FERREIRA, Aurélio Buarque de Holanda. Dicionário eletrônico Aurélio Básico da Língua Portuguesa. Rio de Janeiro: Nova Fronteira, 1975. Disponível em < https://dicionariodoaurelio.com/universidade>. Acessado em 22/04/2016.

MINISTÉRIO DO MEIO AMBIENTE. Secretaria Executiva, Diretoria de Educação Ambiental. Encontros e Caminhos: Formação de Educadores Ambientais e Coletivos Educadores. Brasília.2005.

MINISTÉRIO DA EDUCAÇÃO. Manual de Orientações - PET. Brasília. 2016. Disponível em <http://portal.mec.gov.br/pet/manual-de-orientacoes>. Acessado em 22/04/2016.

PIAGET, Jean; DELVAL, Juan Antonio. La epistemologia genética. A. Redondo, 1970. MINISTÉRIO DA EDUCAÇÃO. Manual de Orientações - PET. Brasília.2016. Disponível em <http://portal.mec.gov.br/pet/manual-de-orientacoes>. Acessado em 22/04/2016. 